\title{
Pseudohexagonal 2D DNA Crystals from Double
}

\section{Crossover Cohesion}

\author{
Baoquan Ding, Ruojie Sha and Nadrian C. Seeman
}

The supplementary information contains the sequences of the two DNA DX triangles used in this work (pages S1 and S2) and a non-denaturing gel demonstrating that the motif migrates as a single band.

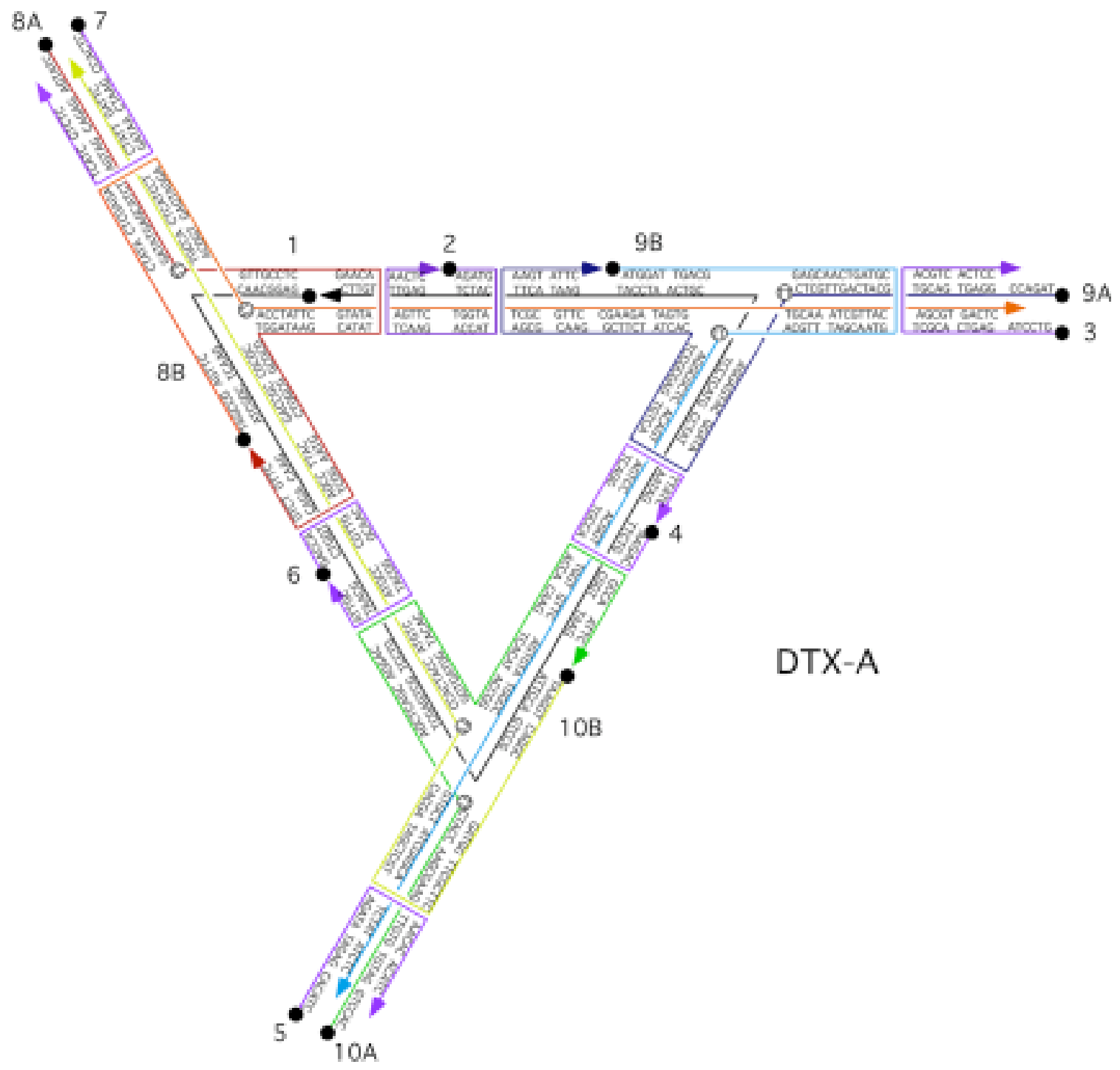




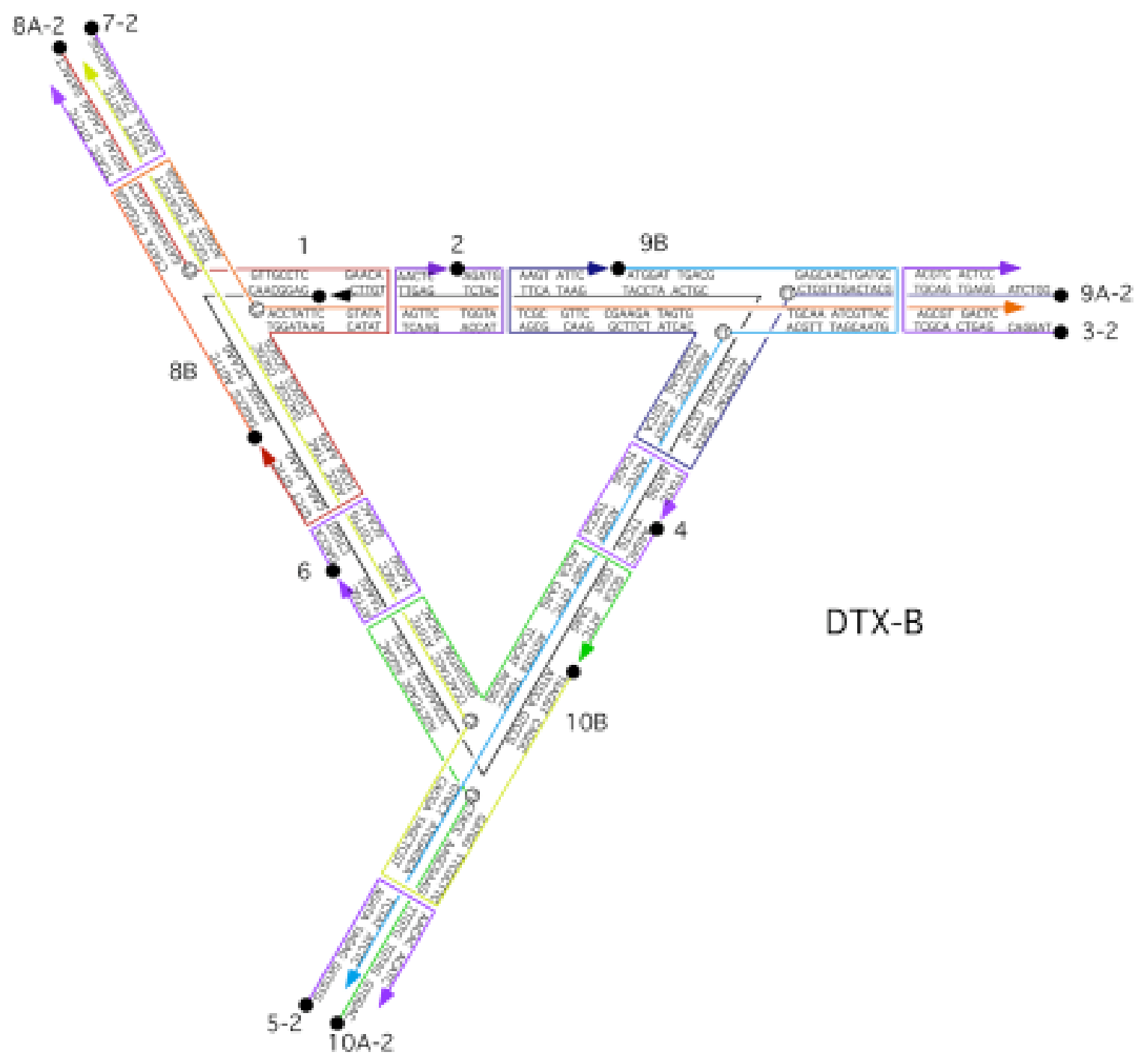


A non-denaturing gel stained with stains-all dye showing that a blunt-ended version of the triangle migrates as a single band. This is a $5 \%$ gel, run in $10.5 \mathrm{mM} \mathrm{Mg}^{2+}$ and TAE buffer at room temperature. The DNA concentration is $0.2 \mu \mathrm{M}$. The insides of the two triangles have the same sequence, differing only by their sticky ends, so only one lane is shown. The marker lane is a 50 bp ladder.

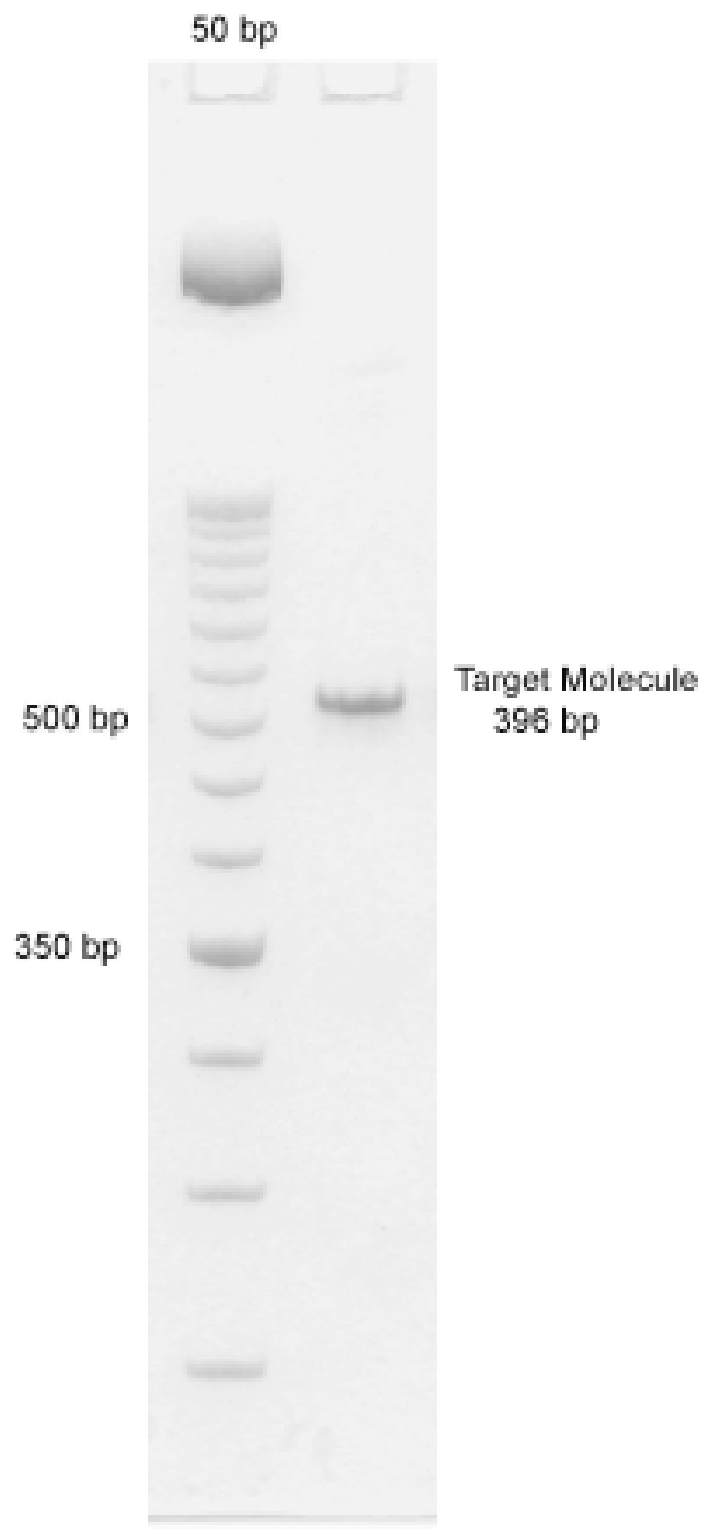

